\section{Avaliação da equivalência semântica da versão em português (Brasil) da Online Cognition Scale}

\author{
Semantic equivalence of the Brazilian Portuguese- \\ language version of the Online Cognition Scale
}

\section{Evaluación de equivalencia semántica de la versión portuguesa (Brasil) de la Online Cognition Scale}

\author{
1 Universidade Federal de \\ São Paulo, São Paulo, Brasil. \\ 2 Universidade de \\ Pernambuco, Recife, Brasil. \\ Correspondência \\ H. R. S. Silva \\ Universidade Federal de \\ São Paulo. \\ Rua Maria Bucalém Haddad \\ 100, bloco F, apto. 32, \\ São Paulo, SP \\ 04125-010, Brasil. \\ hugosaude@gmail.com
}

\begin{abstract}
This study evaluated the semantic equivalence of the Online Cognition Scale in Brazilian Portuguese. The process included five steps: translation, back-translation, technical review, evaluation of semantic equivalence by trained professionals, and evaluation of the instrument for content understanding by a group of professionals $(n=10)$ and students $(n=37)$. The instrument was translated and adapted to Portuguese, showing a high level of verbal comprehension by the target population. The adapted version for use in Brazil resulted in an equivalent instrument from the semantic and content point of view, ready for evaluation of its psychometric qualities in the Brazilian cultural context.
\end{abstract}

Cross-cultural Comparison; Internet; Scales; Validation Studies
Hugo Rafael de Souza e Silva 1

Kelsy Catherina Nema Areco 1

Paulo Bandiera-Paiva 1

Pauliana Valéria Machado Galvão 2

Analia Nusya de Medeiros Garcia 2

Dartiu Xavier da Silveira ${ }^{1}$

\section{Resumo}

Este estudo teve por objetivo realizar a avaliação da equivalência semântica da Online Cognition Scale para o português (Brasil). O processo consistiu em cinco etapas: tradução; retrotradução; revisão técnica e avaliação da equivalência semântica por profissionais capacitados; avaliação do instrumento quanto à compreensão verbal por uma amostra de profissionais $(n=10) e$ estudantes ( $n=37)$. O instrumento foi traduzido e adaptado para o português, apresentando, ao final, excelente nível de compreensão verbal pela população alvo. A versão do instrumento adaptada para uso em nosso meio resultou em um instrumento equivalente do ponto de vista da equivalência semântica e de conteúdo, estando pronto para iniciar o estudo de suas qualidades psicométricas no contexto cultural brasileiro.

Comparação Transcultural; Internet; Escalas; Estudos de Validação 


\section{Introdução}

De 1996 a 2011, 17 escalas de rastreamento foram desenvolvidas para dependência de internet, dentre as quais, podemos citar: InternetRelated Addictive Behavior Inventory (IRABI), Internet Addiction Test (IAT) e Online Cognition Scale (OCS). Entretanto, a maioria desses instrumentos foram pobremente concebidos, sem evidências de confiabilidade ou validade 1,2 . Apenas o IAT foi traduzido e adaptado (alfa de Cronbach $=0,85$ ) para a população brasileira, embora não esteja validado e apresente fragilidades (não ser concebido por modelo próprio, necessite de refinamento e apresente apenas itens comportamentais), promovendo a necessidade científica de se conceber um instrumento que preencha essas lacunas 3 .

A OCS foi desenvolvida e validada em uma amostra de estudantes universitários canadenses, para rastreio do uso problemático de internet, sendo baseada em uma concepção cognitivo-comportamental 4 . Esse instrumento é composto por 36 questões respondidas em uma escala Likert, com pontuação de um (totalmente em desacordo) a sete pontos (totalmente em acordo), divididas em quatro subescalas: solidão/depressão, diminuição do controle dos impulsos, conforto social e distração. Os indicadores de confiabilidade e validade foram considerados bons em estudantes turcos e canadenses 1,5 , e essa escala vem sendo utilizada como instrumento de rastreio de uso problemático de internet 6 .

O objetivo deste trabalho foi avaliar a equivalência semântica da OCS traduzida para o português (Brasil).

\section{Métodos}

A equivalência semântica foi verificada em uma amostra de conveniência de 37 estudantes da Universidade de Pernambuco, dos cursos de medicina, enfermagem, odontologia, educação física e ciências biológicas, com idade média de $19,49$ anos (DP $\pm 2,3)$, sendo $64,86 \%(n=24)$ do sexo feminino. A escolha de realizar o estudo em uma população de estudantes de saúde foi no intuito de replicar outros estudos de validação da OCS 1,5 que usaram amostras de universitários das outras áreas do conhecimento. Embora sempre validado em amostras de universitários, o instrumento também tem sido utilizado em população adulta ${ }^{1}$.

Para esta análise, utilizou-se a abordagem preconizada por Herdman et al. 7 e Reichenheim \& Moraes 8, adotando uma perspectiva univer- salista para a adaptação transcultural. As estratégias utilizadas foram baseadas em estudos similares $3,8,9,10,11,12$, e, para tanto, foi seguido o seguinte percurso metodológico:

1) O instrumento original em inglês foi traduzido para o português (Brasil) por dois tradutores independentes e experientes na tradução de textos de conteúdo científico 3,8,10,11,12,13, apresentando uma versão síntese da tradução;

2) A tradução foi vertida para o inglês, por um tradutor nativo de língua inglesa e por outro tradutor profissional da área da saúde, originando uma versão síntese da retrotradução;

3) A revisão técnica e a avaliação da equivalência semântica foram realizadas por dois psicólogos experientes em adaptação de instrumentos psicométricos, por meio da comparação da versão original e das duas versões apresentadas, enfatizando o significado referencial e o geral do instrumento 3,8,12,13;

4) Um grupo de dez especialistas em saúde mental (dois psiquiatras, quatro psicólogos e quatro enfermeiras) avaliou, empregando um questionário, o grau de compreensão de cada item do instrumento, respondendo: "Você entendeu o que está sendo perguntado?”. As respostas eram do tipo Likert: 0 - não entendi nada; 1 - entendi só um pouco; 2 - entendi mais ou menos; 3 - entendi quase tudo, mas tive algumas dúvidas; 4 - entendi quase tudo; 5 - entendi perfeitamente e não tenho dúvidas. Para obter um bom grau de compreensibilidade, os itens deveriam obter $80 \%$ de respostas 4 e 5 . Para os itens de compreensão insuficiente, foram solicitadas sugestões de mudanças na redação do item, justificando seu raciocínio ${ }^{14}$, sendo elaborada uma nova versão do instrumento;

5) Foi aplicada uma escala numérica verbal adaptada para avaliar o grau de compreensão verbal do instrumento à amostra de estudantes (mesmo procedimento metodológico descrito na 4a etapa para o grupo de profissionais). Após análise das respostas, uma versão final da OCS$\mathrm{BR}$ foi redigida.

Este estudo seguiu a Resolução no 196/96 do Conselho Nacional de Saúde para pesquisa em seres humanos. Todos os participantes assinaram um termo de consentimento livre e esclarecido. O presente estudo foi aprovado pelo Comitê de Ética em Pesquisa da Universidade Federal de São Paulo (UNIFESP), sob o no de CAAE: 10900712.0.0000.5505 e parecer no $173.337 / 12$.

\section{Resultados}

Foi necessário que algumas expressões fossem adaptadas, como em outros estudos de adapta- 
ção transcultural 3,9,10,12, para otimizar a compreensão (Tabela 1). Entretanto, os termos "on-line" e "off-line" foram mantidos ipsis litteris sempre que era viável, pois esses se encontram incorporados ao cotidiano da população brasileira.

A análise da escala OCS-BR pelos profissionais de saúde mental registrou valores médios de compreensão verbal variando entre 3,4 e 5,0 (Tabela 2). Os itens 7, 19 e 28 tiveram grau de compreensibilidade insuficiente, sendo novamente redigidos na tentativa de garantir compreensão verbal, equivalência semântica e as características da população alvo desta adaptação. A redação final dos itens foi evidenciada na Tabela 3.

Após essas alterações, o instrumento foi aplicado aos estudantes para avaliação da compreensão verbal, registrando uma média acima de 4,2 , e todos os itens foram considerados com bom grau de compreensibilidade (Tabela 2), assegurando-se que a população alvo conseguiu compreender o conteúdo semântico da OCS-BR.

\section{Discussão}

A análise da equivalência semântica constitui apenas uma das etapas nos estudos de adaptação transcultural de instrumentos psicométricos e consiste em verificar se a carga subjetiva dos conceitos estabelecidos no instrumento original foi transferida para a cultura alvo da equivalência e se foi captada da mesma forma em ambas as culturas 8 . As estratégias para analisar a equivalência semântica (traduções, retrotraduções, avaliação da equivalência entre as retrotraduções e o original, análise por revisores técnicos, análise por especialistas e pré-teste) foram seguidas como em outros estudos, os quais demonstraram a existência de equivalência semântica nos instrumentos avaliados 3,8,9,10,11,12.
Como pode ser verificado no percurso metodológico, a tradução foi realizada por dois tradutores independentes cujo idioma pátrio era o português, experientes em tradução de documentos, sendo um deles especialista em tradução de textos científicos na área da saúde. Da mesma forma, a retrotradução foi realizada por dois tradutores, um brasileiro e outro nativo da língua inglesa. O perfil desses profissionais foi bastante próximo ao recomendado 15,16 , contribuindo para a qualidade da versão final.

A revisão técnica e da equivalência semântica permitiu verificar a equivalência entre o instrumento original em inglês e a retrotradução, a fim de se garantir a transferência do significado referencial (denotativo) dos termos do instrumento. Para Reichenheim \& Moraes 8, se dois termos possuem o mesmo significado referencial no original e na tradução, pode-se deduzir que ambos possuem equivalência. Outro aspecto verificado foi o significado geral (conotativo) de cada item, sendo comparada a versão original em inglês com o que foi captado na tradução. Essa é uma etapa importante, pois objetiva a transferência dos significados subjetivos de cada termo, pois uma palavra ou frase veiculada com determinada intenção no contexto de origem do instrumento pode não produzir o mesmo efeito na população alvo da versão adaptada, sendo necessária a substituição 6 . Essa preocupação pode ser observada nos itens $2,5,25$ e 30, os quais tiveram termos modificados para garantir a transferência do significado geral.

A análise da equivalência semântica envolveu a verificação do grau de compreensão verbal de especialistas e estudantes. O grupo profissional apresentou uma compreensão verbal insuficiente para os itens 7, 19 e 28. A baixa compreensão dos itens 7 e 19 foi atribuída às traduções stricto sensu deles, que não apreenderam o significado

Tabela 1

Expressões adaptadas no processo de equivalência semântica para a versão em português (Brasil) da Online Cognition Scale (OCS-BR).

\begin{tabular}{lcc}
\hline Item & Tradução literal & Adaptação final \\
\hline 2 & Poucas pessoas me amam além daquelas que & Poucas pessoas gostam de mim além daquelas que \\
conheço on-line & conheço on-line \\
5 & Rush & Euforia \\
13 & As pessoas reclamam que eu uso a internet demais & Pais, amigos e/ou familiares reclamam que eu uso a \\
& Helpless & internet demais \\
30 & Procrastinate & Desamparado
\end{tabular}


Tabela 2

Avaliação da compreensão verbal da versão em português (Brasil) da Online Cognition Scale (OCS-BR).

\begin{tabular}{|c|c|c|}
\hline Itens OCS-BR & $\begin{array}{l}\text { Profissionais }(n=10) \\
\text { Grau de compreensão } \\
\text { Média (DP) }\end{array}$ & $\begin{array}{c}\text { Estudantes }(n=37) \\
\text { Grau de compreensão } \\
\text { Média (DP) }\end{array}$ \\
\hline 1 & $4,9(0,3)$ & $4,5(1,1)$ \\
\hline 2 & $4,4(0,8)$ & $4,3(1,2)$ \\
\hline 3 & $5(0,0)$ & $4,6(1,08)$ \\
\hline 4 & $4,6(0,8)$ & $4,5(0,8)$ \\
\hline 5 & $4,9(0,3)$ & $4,8(0,5)$ \\
\hline 6 & $4,9(0,3)$ & $4,8(0,6)$ \\
\hline 7 & $3,4(1,3)$ & $4,5(1,0)$ \\
\hline 8 & $5(0,0)$ & $5(0,0)$ \\
\hline 9 & $4,7(0,6)$ & $4,9(0,3)$ \\
\hline 10 & $4,9(0,3)$ & $5(0,0)$ \\
\hline 11 & $4,9(0,3)$ & $5(0,0)$ \\
\hline 12 & $5(0,0)$ & $4,7(0,9)$ \\
\hline 13 & $4,6(0,8)$ & $4,5(0,8)$ \\
\hline 14 & $4,8(0,6)$ & $4,4(1,2)$ \\
\hline 15 & $5(0,0)$ & $4,7(0,9)$ \\
\hline 16 & $4,8(0,6)$ & $4,6(0,9)$ \\
\hline 17 & $4,7(0,6)$ & $4,5(1,1)$ \\
\hline 18 & $4,7(0,6)$ & $4,4(1,1)$ \\
\hline 19 & $4,5(0,8)$ & $4,2(1,5)$ \\
\hline 20 & $4,7(0,6)$ & $4,6(1,1)$ \\
\hline 21 & $5(0,0)$ & $4,6(1,0)$ \\
\hline 22 & $5(0,0)$ & $4,9(0,4)$ \\
\hline 23 & $5(0,0)$ & $4,9(0,1)$ \\
\hline 24 & $5(0,0)$ & $4,8(0,4)$ \\
\hline 25 & $5(0,0)$ & $4,7(0,7)$ \\
\hline 26 & $4,8(0,6)$ & $4,5(1,1)$ \\
\hline 27 & $5(0,0)$ & $5(0,0)$ \\
\hline 28 & $4,1(0,9)$ & $4,5(1,0)$ \\
\hline 29 & $4,9(0,3)$ & $4,7(0,8)$ \\
\hline 30 & $5(0,0)$ & $4,7(0,9)$ \\
\hline 31 & $4,7(0,6)$ & $4,7(0,8)$ \\
\hline 32 & $4,9(0,3)$ & $4,2(1,6)$ \\
\hline 33 & $4,8(0,6)$ & $4,4(1,4)$ \\
\hline 34 & $5(0,0)$ & $4,7(0,9)$ \\
\hline 35 & $4,8(0,6)$ & $4,5(1,3)$ \\
\hline 36 & $5(0,0)$ & $4,8(0,6)$ \\
\hline Total & $4,7(0,2)$ & $4,6(0,4)$ \\
\hline
\end{tabular}

DP: desvio-padrão.

geral (conotativo), devido à tradução literal de um termo não refletir necessariamente uma mesma reação emocional ou afetiva em diferentes culturas ${ }^{8}$. A inadequação do item 28 relacionou-se à redação. Realizados os devidos ajustes, a avaliação da compreensão verbal pelos estu- dantes demonstrou que o instrumento tornou-se de fácil compreensão, não havendo mais nenhuma sugestão pelos participantes para alterações estruturais na OCS-BR. 
Tabela 3

Comparação entre a versão original em inglês, tradução, retrotradução e versão final da Online Cognition Scale (OCS).

\begin{tabular}{|c|c|c|c|c|}
\hline Itens & Versão original & Síntese das traduções & Síntese das retrotraduções & Versão final em português \\
\hline 1 & I am most comfortable online. & $\begin{array}{l}\text { Eu me sinto mais confortável } \\
\text { on-line. }\end{array}$ & I feel more comfortable online. & $\begin{array}{l}\text { Eu me sinto mais confortável } \\
\text { on-line. }\end{array}$ \\
\hline 2 & $\begin{array}{c}\text { Few people love me other than } \\
\text { those I know online. }\end{array}$ & $\begin{array}{c}\text { Poucas pessoas me aceitam } \\
\text { além daquelas que eu conheço } \\
\text { on-line. }\end{array}$ & $\begin{array}{l}\text { Few people accept me apart } \\
\text { from those I know online. }\end{array}$ & $\begin{array}{l}\text { Poucas pessoas gostam de } \\
\text { mim além daquelas que eu } \\
\text { conheço on-line. }\end{array}$ \\
\hline 3 & $\begin{array}{l}\text { I feel safest when I am on the } \\
\text { internet. }\end{array}$ & $\begin{array}{l}\text { Eu me sinto mais seguro(a) } \\
\text { quando estou na internet. }\end{array}$ & $\begin{array}{l}\text { I feel safer when I'm using the } \\
\text { internet. }\end{array}$ & $\begin{array}{l}\text { Eu me sinto mais seguro(a) } \\
\text { quando estou na internet. }\end{array}$ \\
\hline 4 & $\begin{array}{c}\text { I often keep thinking about } \\
\text { something I experienced online } \\
\text { well after I have logged off. }\end{array}$ & $\begin{array}{l}\text { Eu frequentemente fico } \\
\text { pensando sobre algo que eu } \\
\text { experimentei on-line depois de } \\
\text { já ter me desconectado. }\end{array}$ & $\begin{array}{l}\text { I often wonder about something } \\
\text { I have experienced online after I } \\
\text { have already disconnected. }\end{array}$ & $\begin{array}{l}\text { Eu frequentemente fico } \\
\text { pensando sobre algo que eu } \\
\text { experimentei on-line depois } \\
\text { de já ter me desconectado. }\end{array}$ \\
\hline 5 & $\begin{array}{l}\text { When I am on the internet, I } \\
\text { often feel a kind of "rush" or } \\
\text { emotional high. }\end{array}$ & $\begin{array}{l}\text { Quando estou na internet, eu } \\
\text { geralmente sinto um tipo de } \\
\text { excitação. }\end{array}$ & $\begin{array}{l}\text { When I'm on the internet, I } \\
\text { usually feel a kind of excitement. }\end{array}$ & $\begin{array}{l}\text { Quando estou na internet, } \\
\text { eu geralmente sinto um tipo } \\
\text { de euforia. }\end{array}$ \\
\hline 6 & $\begin{array}{c}\text { You can get to know a person } \\
\text { better on the internet than in } \\
\text { person. }\end{array}$ & $\begin{array}{c}\text { Você pode conhecer uma } \\
\text { pessoa melhor na internet do } \\
\text { que pessoalmente. }\end{array}$ & $\begin{array}{l}\text { You can know someone better } \\
\text { on the internet than in person. }\end{array}$ & $\begin{array}{l}\text { Você pode conhecer uma } \\
\text { pessoa melhor na internet } \\
\text { do que pessoalmente. }\end{array}$ \\
\hline 7 & $\begin{array}{l}\text { I often find it peaceful to be } \\
\text { online. }\end{array}$ & $\begin{array}{l}\text { Eu geralmente considero } \\
\text { pacífico estar on-line. }\end{array}$ & $\begin{array}{l}\text { I generally believe it is peaceful } \\
\text { being online }\end{array}$ & $\begin{array}{l}\text { Quando estou on-line, eu } \\
\text { me sinto tranquilo. }\end{array}$ \\
\hline 8 & I can be myself online. & $\begin{array}{l}\text { Eu posso ser eu mesmo(a) on- } \\
\text { line. }\end{array}$ & I can be myself online. & $\begin{array}{l}\text { Eu posso ser eu mesmo(a) } \\
\text { on-line. }\end{array}$ \\
\hline 9 & $\begin{array}{l}\text { I get more respect online than } \\
\text { 'in real life'. }\end{array}$ & $\begin{array}{l}\text { Eu sou mais respeitado(a) on- } \\
\text { line que na "vida real". }\end{array}$ & $\begin{array}{c}\text { I am more respected online than } \\
\text { in "real life". }\end{array}$ & $\begin{array}{l}\text { Eu sou mais respeitado(a) } \\
\text { on-line do que na "vida } \\
\text { real". }\end{array}$ \\
\hline 10 & $\begin{array}{l}\text { I use the internet more than I } \\
\text { ought to. }\end{array}$ & $\begin{array}{l}\text { Eu uso a internet mais do que } \\
\text { eu deveria. }\end{array}$ & $\begin{array}{l}\text { I use the internet more than I } \\
\text { should. }\end{array}$ & $\begin{array}{c}\text { Eu uso a internet mais do } \\
\text { que eu deveria. }\end{array}$ \\
\hline 11 & $\begin{array}{l}\text { People complain that I use the } \\
\text { internet too much. }\end{array}$ & $\begin{array}{c}\text { As pessoas reclamam que eu } \\
\text { uso a internet demais. }\end{array}$ & $\begin{array}{l}\text { People complain that I use the } \\
\text { internet too much. }\end{array}$ & $\begin{array}{l}\text { As pessoas (pais, amigos e } \\
\text { familiares) reclamam que eu } \\
\text { uso a internet demais. }\end{array}$ \\
\hline 12 & $\begin{array}{l}\text { I never stay on longer than I had } \\
\text { planned. }\end{array}$ & $\begin{array}{c}\text { Eu nunca fico on-line por } \\
\text { mais tempo do que eu havia } \\
\text { planejado. }\end{array}$ & $\begin{array}{l}\text { I never stay online longer than I } \\
\text { had planned. }\end{array}$ & $\begin{array}{c}\text { Eu nunca fico on-line por } \\
\text { mais tempo do que eu havia } \\
\text { planejado. }\end{array}$ \\
\hline 13 & $\begin{array}{c}\text { People accept me for who I am } \\
\text { online. }\end{array}$ & $\begin{array}{l}\text { As pessoas me aceitam pelo que } \\
\text { eu sou on-line. }\end{array}$ & $\begin{array}{c}\text { People accept me for what I am } \\
\text { online. }\end{array}$ & $\begin{array}{c}\text { As pessoas me aceitam pelo } \\
\text { que eu sou on-line. }\end{array}$ \\
\hline 14 & $\begin{array}{l}\text { Online relationships can be } \\
\text { more fulfilling than offline ones. }\end{array}$ & $\begin{array}{c}\text { Relacionamentos on-line podem } \\
\text { ser mais gratificantes do que os } \\
\text { off-line. }\end{array}$ & $\begin{array}{c}\text { Online relationships can be } \\
\text { more rewarding than off-line } \\
\text { ones. }\end{array}$ & $\begin{array}{c}\text { Relacionamentos on-line } \\
\text { podem ser mais gratificantes } \\
\text { do que os off-line. }\end{array}$ \\
\hline 15 & $\begin{array}{l}\text { When I am not online, I often } \\
\text { think about the internet. }\end{array}$ & $\begin{array}{l}\text { Quando não estou on-line, eu } \\
\text { frequentemente penso sobre a } \\
\text { internet. }\end{array}$ & $\begin{array}{l}\text { When I'm not online, I often } \\
\text { think about the internet. }\end{array}$ & $\begin{array}{l}\text { Quando não estou on-line, } \\
\text { eu frequentemente penso } \\
\text { sobre a internet. }\end{array}$ \\
\hline 16 & $\begin{array}{c}\text { I am at my best when I am } \\
\text { online. }\end{array}$ & $\begin{array}{c}\text { Estou no meu melhor momento } \\
\text { quando estou na internet. }\end{array}$ & $\begin{array}{l}\text { I'm at my best moment when I'm } \\
\text { on the internet. }\end{array}$ & $\begin{array}{l}\text { Estou no meu melhor } \\
\text { momento quando estou na } \\
\text { internet. }\end{array}$ \\
\hline 17 & $\begin{array}{l}\text { The offline world is less exciting } \\
\text { than what you can do online. }\end{array}$ & $\begin{array}{l}\text { O mundo off-line é menos } \\
\text { excitante do que o que se pode } \\
\text { fazer on-line. }\end{array}$ & $\begin{array}{l}\text { The offline world is less exciting } \\
\text { than what one can do online. }\end{array}$ & $\begin{array}{l}\text { O mundo off-line é menos } \\
\text { excitante do que o que se } \\
\text { pode fazer on-line. }\end{array}$ \\
\hline
\end{tabular}

(continua) 
Tabela 3 (continuação)

\begin{tabular}{|c|c|c|c|c|}
\hline Itens & Versão original & Síntese das traduções & Síntese das retrotraduções & Versão final em português \\
\hline 18 & $\begin{array}{c}\text { I wish my friends and family } \\
\text { knew how people regard me } \\
\text { online. }\end{array}$ & $\begin{array}{l}\text { Eu gostaria que meus amigos e } \\
\text { familiares soubessem como as } \\
\text { pessoas me veem on-line. }\end{array}$ & $\begin{array}{l}\text { I would like my friends and } \\
\text { family members to know how } \\
\text { people see me online. }\end{array}$ & $\begin{array}{c}\text { Eu gostaria que meus } \\
\text { amigos e familiares } \\
\text { soubessem como as pessoas } \\
\text { me respeitam on-line. }\end{array}$ \\
\hline 19 & $\begin{array}{c}\text { The internet is more 'real' than } \\
\text { real life. }\end{array}$ & $\begin{array}{c}\text { A internet é mais "real" que a } \\
\text { vida real. }\end{array}$ & $\begin{array}{c}\text { The internet is more "real" than } \\
\text { real life. }\end{array}$ & $\begin{array}{l}\text { O mundo virtual é mais } \\
\text { realista que a vida real. }\end{array}$ \\
\hline 20 & $\begin{array}{l}\text { When I am online I don't think } \\
\text { about my responsibilities. }\end{array}$ & $\begin{array}{l}\text { Quando eu estou on-line, } \\
\text { eu não penso sobre minhas } \\
\text { responsabilidades. }\end{array}$ & $\begin{array}{l}\text { When I'm online, I do not think } \\
\text { about my responsibilities. }\end{array}$ & $\begin{array}{l}\text { Quando eu estou on-line, } \\
\text { eu não penso sobre minhas } \\
\text { responsabilidades. }\end{array}$ \\
\hline 21 & $\begin{array}{l}\text { I can't stop thinking about the } \\
\text { internet. }\end{array}$ & $\begin{array}{l}\text { Eu não consigo parar de pensar } \\
\text { sobre a internet. }\end{array}$ & $\begin{array}{l}\text { I cannot stop thinking about the } \\
\text { internet. }\end{array}$ & $\begin{array}{l}\text { Eu não consigo parar de } \\
\text { pensar sobre a internet. }\end{array}$ \\
\hline 22 & $\begin{array}{l}\text { I am less lonely when I am } \\
\text { online. }\end{array}$ & $\begin{array}{l}\text { Eu fico menos solitário quando } \\
\text { estou na internet. }\end{array}$ & $\begin{array}{l}\text { I'm less lonely when I'm on the } \\
\text { internet. }\end{array}$ & $\begin{array}{l}\text { Eu fico menos solitário } \\
\text { quando estou on-line. }\end{array}$ \\
\hline 23 & $\begin{array}{l}\text { I cannot see myself ever without } \\
\text { the internet for too long. }\end{array}$ & $\begin{array}{c}\text { Eu não posso me imaginar sem } \\
\text { a internet por muito tempo. }\end{array}$ & $\begin{array}{l}\text { I cannot imagine myself for a } \\
\text { long time without the internet. }\end{array}$ & $\begin{array}{l}\text { Eu não posso me imaginar } \\
\text { sem a internet por muito } \\
\text { tempo. }\end{array}$ \\
\hline 24 & $\begin{array}{l}\text { The internet is an important part } \\
\text { of my life. }\end{array}$ & $\begin{array}{l}\text { A internet é uma parte } \\
\text { importante da minha vida. }\end{array}$ & $\begin{array}{l}\text { The internet is an important part } \\
\text { of my life. }\end{array}$ & $\begin{array}{l}\text { A internet é uma parte } \\
\text { importante da minha vida. }\end{array}$ \\
\hline 25 & $\begin{array}{l}\text { I feel helpless when I don't have } \\
\text { access to the internet. }\end{array}$ & $\begin{array}{c}\text { Eu me sinto desamparado } \\
\text { quando eu não tenho acesso à } \\
\text { internet. }\end{array}$ & $\begin{array}{c}\text { I feel helpless when I do not } \\
\text { have internet access. }\end{array}$ & $\begin{array}{c}\text { Eu me sinto desamparado } \\
\text { quando eu não tenho acesso } \\
\text { à internet. }\end{array}$ \\
\hline 26 & $\begin{array}{l}\text { I say or do things on the internet } \\
\text { that I could never do offline. }\end{array}$ & $\begin{array}{l}\text { Eu digo ou faço coisas na } \\
\text { internet que eu jamais poderia } \\
\text { fazer off-line. }\end{array}$ & $\begin{array}{l}\text { I say or do things on the internet } \\
\text { that I could never do offline. }\end{array}$ & $\begin{array}{c}\text { Eu digo ou faço coisas } \\
\text { na internet que eu jamais } \\
\text { poderia fazer off-line. }\end{array}$ \\
\hline 27 & $\begin{array}{l}\text { When I have nothing better to } \\
\text { do, I go online. }\end{array}$ & $\begin{array}{l}\text { Quando eu não tenho nada } \\
\text { melhor para fazer, eu fico on- } \\
\text { line. }\end{array}$ & $\begin{array}{l}\text { When I have nothing better to } \\
\text { do, I go online. }\end{array}$ & $\begin{array}{c}\text { Quando eu não tenho nada } \\
\text { melhor para fazer, eu fico } \\
\text { on-line. }\end{array}$ \\
\hline 28 & $\begin{array}{l}\text { I find that I go online more when } \\
\text { I have something else I am } \\
\text { supposed to do. }\end{array}$ & $\begin{array}{l}\text { Acredito que fico on-line mais } \\
\text { nos momentos quando tenho } \\
\text { alguma outra coisa que eu } \\
\text { deveria fazer. }\end{array}$ & $\begin{array}{l}\text { I think I go online more at times } \\
\text { when I have something else I } \\
\text { should be doing. }\end{array}$ & $\begin{array}{l}\text { Acredito que fico on-line } \\
\text { por mais tempo quando } \\
\text { tenho alguma outra tarefa a } \\
\text { cumprir. }\end{array}$ \\
\hline 29 & $\begin{array}{l}\text { When I am online, I don't need } \\
\text { to think about offline problems. }\end{array}$ & $\begin{array}{l}\text { Quando eu estou on-line, } \\
\text { eu não preciso pensar sobre } \\
\text { problemas que tenho off-line. }\end{array}$ & $\begin{array}{c}\text { When I'm online, I do not need } \\
\text { to think about problems that I } \\
\text { have offline. }\end{array}$ & $\begin{array}{l}\text { Quando estou on-line, eu } \\
\text { não preciso pensar sobre } \\
\text { problemas que tenho fora } \\
\text { da internet. }\end{array}$ \\
\hline 30 & $\begin{array}{l}\text { I sometimes use the internet to } \\
\text { procrastinate. }\end{array}$ & $\begin{array}{c}\text { Eu às vezes uso a internet para } \\
\text { procrastinar. }\end{array}$ & $\begin{array}{l}\text { I sometimes use the internet to } \\
\text { procrastinate. }\end{array}$ & $\begin{array}{c}\text { Eu às vezes uso a } \\
\text { internet para adiar outras } \\
\text { obrigações. }\end{array}$ \\
\hline 31 & $\begin{array}{l}\text { When I am online, I can be } \\
\text { carefree. }\end{array}$ & $\begin{array}{l}\text { Quando eu estou on-line, eu } \\
\text { posso ficar despreocupado(a). }\end{array}$ & $\begin{array}{c}\text { When I am online, I can stop } \\
\text { worrying }\end{array}$ & $\begin{array}{l}\text { Quando eu estou on- } \\
\text { line, eu posso ficar } \\
\text { despreocupado(a). }\end{array}$ \\
\hline 32 & $\begin{array}{l}\text { I often use the internet to avoid } \\
\text { doing unpleasant things. }\end{array}$ & $\begin{array}{l}\text { Eu frequentemente uso a } \\
\text { internet para evitar fazer coisas } \\
\text { desagradáveis. }\end{array}$ & $\begin{array}{l}\text { I often use the internet to avoid } \\
\text { doing unpleasant things. }\end{array}$ & $\begin{array}{l}\text { Eu frequentemente uso a } \\
\text { internet para evitar fazer } \\
\text { coisas desagradáveis. }\end{array}$ \\
\hline 33 & $\begin{array}{l}\text { Using the internet is a way to } \\
\text { forget about the things I must } \\
\text { do but really don't want to do. }\end{array}$ & $\begin{array}{l}\text { Usar a internet é uma forma de } \\
\text { esquecer coisas que tenho que } \\
\text { fazer, mas realmente não quero } \\
\text { fazer. }\end{array}$ & $\begin{array}{l}\text { Using the internet is a way of } \\
\text { forgetting things I have to do } \\
\text { but do not really want to do. }\end{array}$ & $\begin{array}{l}\text { Usar a internet é uma } \\
\text { forma de esquecer coisas } \\
\text { que tenho que fazer, mas } \\
\text { realmente não quero } \\
\text { fazê-las. }\end{array}$ \\
\hline
\end{tabular}

(continua) 
Tabela 3 (continuação)

\begin{tabular}{|c|c|c|c|c|}
\hline Itens & Versão original & Síntese das traduções & Síntese das retrotraduções & Versão final em português \\
\hline 34 & $\begin{array}{l}\text { Even though there are times } \\
\text { when I would like to, I can't cut } \\
\text { down on my use of the internet. }\end{array}$ & $\begin{array}{l}\text { Embora haja momentos em que } \\
\text { eu gostaria de diminuir meu } \\
\text { uso da internet, eu não consigo } \\
\text { reduzi-lo. }\end{array}$ & $\begin{array}{c}\text { Although there are times when } \\
\text { I would like to reduce my use } \\
\text { of the internet, I cannot cut it } \\
\text { down. }\end{array}$ & $\begin{array}{l}\text { Embora haja momentos em } \\
\text { que eu gostaria de diminuir } \\
\text { meu uso da internet, eu não } \\
\text { consigo reduzi-lo. }\end{array}$ \\
\hline 35 & $\begin{array}{l}\text { I am bothered by my inability to } \\
\text { stop using the internet so much. }\end{array}$ & $\begin{array}{l}\text { Eu me sinto incomodado pela } \\
\text { falta de capacidade para parar } \\
\text { de usar tanto a internet. }\end{array}$ & $\begin{array}{c}\text { I feel bothered by the lack of } \\
\text { ability to stop using the internet } \\
\text { so much. }\end{array}$ & $\begin{array}{l}\text { Me sinto incomodado pela } \\
\text { minha falta de capacidade } \\
\text { para interromper o longo } \\
\text { tempo que passo na } \\
\text { internet. }\end{array}$ \\
\hline 36 & $\begin{array}{l}\text { My use of the internet } \\
\text { sometimes seems beyond my } \\
\text { control. }\end{array}$ & $\begin{array}{l}\text { Meu uso da internet às vezes } \\
\text { parece estar fora do meu } \\
\text { controle. }\end{array}$ & $\begin{array}{l}\text { My use of the internet } \\
\text { sometimes seems out of my } \\
\text { control. }\end{array}$ & $\begin{array}{l}\text { Meu uso da internet às } \\
\text { vezes parece estar fora do } \\
\text { meu controle. }\end{array}$ \\
\hline Respostas * & $\begin{array}{l}\text { (1) Strongly disagree } \\
\text { (2) Moderately disagree } \\
\text { (3) Slightly disagree }\end{array}$ & $\begin{array}{l}\text { (1) Discordo totalmente } \\
\text { (2) Discordo moderadamente } \\
\text { (3) Discordo levemente }\end{array}$ & $\begin{array}{l}\text { (1) Strongly disagree } \\
\text { (2) Moderately disagree } \\
\text { (3) Slightly disagree }\end{array}$ & $\begin{array}{l}\text { (1) Discordo totalmente } \\
\text { (2) Discordo } \\
\text { moderadamente }\end{array}$ \\
\hline & $\begin{array}{l}\text { (4) Neither agree nor disagree } \\
\text { (5) Slightly agree } \\
\text { (6) Moderately agree }\end{array}$ & $\begin{array}{l}\text { (4) Não concordo, nem discordo } \\
\text { (5) Concordo levemente } \\
\text { (6) Concordo moderadamente }\end{array}$ & $\begin{array}{l}\text { (4) Neither agree nor disagree } \\
\text { (5) Slightly agree } \\
\text { (6) Moderately agree }\end{array}$ & $\begin{array}{l}\text { (3) Discordo levemente } \\
\text { (4) Nem concordo, nem } \\
\text { discordo }\end{array}$ \\
\hline & (7) Strongly agree & (7) Concordo fortemente & (7) Strongly agree & $\begin{array}{l}\text { (5) Concordo levemente } \\
\text { (6) Concordo } \\
\text { moderadamente } \\
\text { (7) Concordo totalmente }\end{array}$ \\
\hline
\end{tabular}

* Todas as questões possuíram as mesmas opções de respostas, pois se trata de uma escala do tipo Likert, com valores de 1 a 7.

Nota: subescalas da OCS-BR - conforto social: 1, 3, 6, 7, 8, 9, 13, 14, 16, 18, 19, 26, 31; solidão/depressão: 2, 22, 23, 24, 25, 35; impulsividade: 4, 5, 10, 11, 12, 15, 17, 21, 34, 36 e distração: 20, 27, 28, 29, 30, 32, 33.

\section{Conclusão}

Conclui-se, considerando o rigor metodológico e as evidências demonstradas nas estratégias de avaliação da equivalência semântica desenvolvidas neste estudo, que a versão brasileira da OCS foi bem compreendida pela amostra, conservou os elementos de equivalência semântica entre os termos e se mostrou adequada para a realização do estudo de suas qualidades psicométricas e de validação. 


\section{Resumen}

El objetivo de este estudio fue llevar a cabo la evaluación de la equivalencia semántica de la Online Cognition Scale en portugués (Brasil). El proceso consistió en cinco etapas: traducción, retrotraducción, revisión técnica y evaluación de la equivalencia semántica de los profesionales; habilitación de instrumentos como la comprensión verbal por una muestra de profesionales $(n=$ 10) y estudiantes $(n=37)$. El instrumento fue traducido y adaptado al portugués, con un excelente nivel final de comprensión verbal por parte de la población objetivo. La versión adaptada del instrumento para su uso en nuestro contexto, que dio como resultado un instrumento equivalente desde el punto de vista semántico y del contenido, está lista para que comience el estudio de sus propiedades psicométricas en el contexto cultural brasileño.

Comparación Transcultural; Internet; Escalas; Estudios de Validación

\section{Referências}

1. Davis RA, Flett GL, Besser A. Validation of a new scale for measuring problematic internet use: implications for pre-employment screening. Cyberpsychol Behav 2002; 5:331-45.

2. Berner JE, Santander TJ. Abuso y dependencia de internet: la epidemia y su controversia. Rev Chil Neuro-Psiquiatr 2012; 50:181-90.

3. Conti MA, Jardim AP, Hearst N, Cordás TA, Tavares H. Avaliação da equivalência semântica e consistência interna de uma versão em português do Internet Addiction Test (IAT). Rev Psiquiatr Clín 2012; 39:106-10.

4. Davis RA. A cognitive-behavioral model of pathological internet use. Comput Hum Behav 2001; 17:187-95.

5. Ozcan N, Buzlu S. An assistive tool in determining problematic internet use: validity and reliability of the Online Cognition Scale in a sample of university students. Journal of Dependence 2005; 6:19-26.

6. Nalwa K, Anand AP. Internet addiction in students: a cause of concern. Cyberpsychol Behav 2003; 6:653-6.

7. Herdman M, Fox-Rushby J, Badia X. A model of equivalence in the cultural adaptation of HRQoL instruments: the universalist approach. Qual Life Res 1998; 7:323-35.

8. Reichenheim ME, Moraes CL. Operacionalização de adaptação transcultural de instrumentos de aferição usados em epidemiologia. Rev Saúde Pública 2007; 41:665-73.

9. Kachani AT, Barbosa ALR, Brasiliano S, Cordás TA, Hochgraf PB, Conti MA. Tradução, adaptação transcultural para o português (Brasil) e validação de conteúdo da Body Checking Cognitions Scale (BCCS). Rev Psiquiatr Clín 2011; 38:13-8.

\section{Colaboradores}

H. R. S. Silva e D. X. Silveira participaram da concepção, projeto, análise e interpretação dos dados, redação do artigo e aprovação final da versão a ser publicada. $\mathrm{K}$ C. N. Areco, P. Bandiera-Paiva e P. V. M. Galvão contribuíram na análise e interpretação dos dados, revisão crítica relevante do conteúdo intelectual e aprovação final da versão a ser publicada. A. N. M. Garcia colaborou na concepção e projeto, revisão crítica relevante do conteúdo intelectual e aprovação final da versão a ser publicada. Todos os autores foram responsáveis por todos os aspectos do trabalho na garantia da exatidão e da integridade de qualquer parte da obra.

\section{Agradecimentos}

Agradecemos aos profissionais e estudantes envolvidos no processo de adaptação transcultural.
10. Teixeira PC, Hearst N, Matsudo SMM, Cordás TA Conti MA. Adaptação transcultural: tradução e validação de conteúdo da versão brasileira do Commitment Exercise Scale. Rev Psiquiatr Clín 2011; 38:24-8.

11. Conti MA, Scagliusi F, Queiroz GKO, Hearst N, Cordás TA. Adaptação transcultural: tradução e validação de conteúdo para o idioma português do modelo da Tripartite Influence Scale de insatisfação corporal. Cad Saúde Pública 2010; 26:503-13.

12. Toledo EL, Taragano R, Cordás TA, Abreu CN, Hearst N, Conti MA. Adaptação transcultural da Massachusetts General Hospital (MGH) Hairpulling Scale para o idioma português (Brasil). Rev Psiquaitr Clín 2011; 38:178-83.

13. Grassi-Oliveira R, Stein LM, Pezzi JC. Tradução e validação de conteúdo da versão em português do Childhood Trauma Questionnaire. Rev Saúde Pública 2006; 40:249-55.

14. Conti MA, Latorre MRDO. Estudo de validação e reprodutibilidade de uma escala de silhueta para adolescentes. Psicol Estud 2009; 14:699-706.

15. Guillemin F, Bombardier C, Beaton D. Cross-cultural adaptation of health-related quality of life measures: literature review and proposed guidelines. J Clin Epidemiol 1993; 46:1417-32.

16. Perneger TV, Leplège A, Etter J-F. Cross-cultural adaptation of a psychometric instrument: two methods compared. J Clin Epidemiol 1999; 52:1037-46.

Recebido em 24/Ago/2013

Versão final reapresentada em 01/Fev/2014

Aprovado em 07/Mar/2014 